\title{
A New Design Process for Viewer Participation in Interactive TV Program: Focused on the Interactive TV Game Show Hae-un-dae
}

\author{
Jeongbeom Shin, Hyun Jung Kim, Jea In Kim, Bong Gwan Jun, and Chung-Kon Shi \\ Graduate School of Culture Technology, KAIST, Daejeon, Republic of Korea \\ \{jeongbeom, claudiakim, jeainkim86, bonggwan, chungkon\} @kaist.ac.kr
}

\begin{abstract}
It is no easy thing to insert viewer participation seamlessly within a narrative structure when planning interactive TV program, and moreover there are not any existing processes to solve such difficulty in practice. Thus, in this paper, we proposed a new design process to be suitable to map out viewer participation of interactive TV program and demonstrated the application of our design process to the development of the iTV game show Hae-un-dae.
\end{abstract}

Keywords: interactive television, viewer participation, design process.

\section{Introduction}

As the new interactive services such as cloud computing and second screen have appeared, there have been various attempts related to interactive TV [iTV] program. However, most of them mainly concentrated on technical issues rather than attempts to realize viewers' latent needs of interactivity in traditional television so far. [1] To offer rich interactive experiences to the viewers, it is essential to link seamlessly between viewer participation and program narrative ${ }^{1}$. In this regard, several researches underlined the middle ground between a compelling story and meaningful interaction. [2][3][4] Nevertheless, they could not suggest any specific methodologies, and the existing process for devising TV format would not be helpful because it was established to consider viewer participation as a secondary element or distinct from program narrative. [5] Therefore, we suggested a new design process to achieve a balance between viewer participation and program narrative. This design process has been formed through the following procedure. First, we considered the key elements of interactive experience based on narrative revolving around alternate reality game [ARG], interactive drama and so on, which lay stress on the balance between interactivity and narrative structure. Next, we took note of the persona-based scenario in

\footnotetext{
${ }^{1}$ TV program narrative is generally created by producers and should explain the elements of who, what, when, where, how, and why about itself. In this regard, Justin Scroggie (Format Doctor) devised "format grid" of television program that consists of the following elements: genre, core subject, main people, do what, and achieve what.
} 
Human Computer Interaction and the framework of behavior chain for online participation as the design process that can reflect the key elements effectively. Finally, we constructed a new design process by integrating and modifying the two methods for the planning process of iTV program. Lastly, We showed how it was applied to the iTV game show Hae-un-dae $e^{2}$ in practice.

\section{The Key Elements of Interactive Experience Based on Narrative}

\subsection{First-Person Role-Playing and Agency}

The audience is just a player in the participatory contents such as ARG or interactive drama. The players take the first-person point of view and perform roles and tasks derived from a narrative context. Kim pointed out that viewer participation of interactive programs is possible to be realized by giving a certain role to a viewer. [6] Laurel also gave importance to the first-person experience, that is, the ability to do something directly in terms of promoting engagement. [7] Furthermore, Murray emphasized that the players invent their own characters within the conventions of the controlling fictional genre. [8]

By the way, this first-person experience is indispensable to agency. [7] Agency is the satisfying power to take meaningful actions and see the results of players' decisions and choices. [8] Therefore, it is imperative that the players have agency experience to sustain their first-person role-playing. Moreover, the agency is aroused at the intersection that interactivity is interlinked with narrativity. Mateas said that players can experience agency when there is a balance between the material and formal constraints. In his argument, the material constraint means actions by players, and the formal constraint indicates dramatic probabilities, namely, plot. [9]

\subsection{Participation Level, Casting, and Dynamic Relationship}

There is a level difference of players' participation depending on their time, skill, and inclination in ARG. Although some players fell short on one of these dimensions, they should not be penalized in terms of progression of a story. [10] All the players should be given certain roles commensurate with their level to make absorbing games. For this, pervasive games offer various roles such as player, participant, spectator, and even refuser according to the participation level. [11]

Another important point to notice, here is, that this kind of assigning roles can create dynamic relationships to enliven meaningful interactions. For instance, all the

\footnotetext{
${ }^{2}$ The Hae-un-dae is the academic-industrial collaboration between KAIST (Korea Advanced Institute of Science and Technology) and Nmedia (the television production company).
} 
participants of Wer rettet Dina Foxx $x^{3}$ became the assistants to clear off all suspicions of the heroine, Dina Foxx. According to the participation level, however, the highlevel participants were given the ARG required a lot of time and energy, whereas the low-level participants were offered the graphic adventure game required only their point and click actions. Thus, the dynamic relationship provides a foundation to design concrete interaction activities suitable for the participants' respective roles.

\section{The Design Processes for User Participation}

\subsection{The Persona-Based Scenario}

The persona-based scenario has been mostly used to design user experience. The persona is an imaginary character as a representative type of actual users, which describes their goals, acts, and attitudes. It is practical to understand motivations and behavior patterns of actual users exactly because it is formed on the basis of qualitative and quantitative researches on them. The scenario is useful to draw an outline of user experience vividly at the early stage of development of product and service. It is to narrate a series of events by nature, therefore, it can handle not only superficial experiences but also their inner emotions. In addition, it is helpful to organize and manage all possible variables in phases. [12][13]

The persona-based scenario has the potential to be utilized effectively for designing viewer participation in iTV program. Most of all, it is simply done to assign the first-person roles to the viewers when using the method. Because the personas are presented as an imaginary personality with a human face image, the designers can empathize with the viewers readily and assume their specific behavior patterns reasonably. They can also devise several dynamic relationships with the personas in order to attract more viewers to engage in iTV program.

On the one hand, the scenario helps that the designers describe the persona forms some behavior patterns to achieve their goals. In particular, this method conveys viewer participation as a story, and thereby the whole stakeholders can exchange their ideas about the agenda smoothly. It is apprehended that explanations or enumerations create unnecessary confusion because the participation structure of iTV program is complicated. The scenario fulfills the function that unravels the complexity of that structure. Besides, it can describe even the personas' inner emotions as well as their overall interactive experiences so that the designers can check the completed viewer participation for embodying agency.

However, the persona-based scenario has to be modified for the practice of iTV program. Designing for viewer participation in iTV program has a different starting point with one of user experience design of product and service. The latter usually begins with grasping users' hidden needs, whereas the former must start with seeking $\mathrm{g}$ viewers' roles within program narrative. In the strict sense, the first-person

\footnotetext{
${ }^{3}$ Wer rettet Dina Foxx was the trans-media project marketed as an interactive crime story, which had been co-produced and helmed by ZDF (the German television network), teamWorx, and UFA-lab for 6 weeks from April 20, 2011.
} 
role-playing is accompanied by all the viewers' common desire that they want to experience a compelling narrative.

\subsection{The Framework of the Behavior Chain for Online Participation}

Fogg and Eckles proposed the framework of the behavior chain to analyze how the leading web services such as LinkedIN and Flickr attract online participation from users effectively. Their framework consists of three phases; the first is the discovery phase whose goal is to make users recognize a web service and visit it, or, conversely, the users visit the web service and then learn about it. The second is the superficial involvement phase in which the users decide to make use of the web service and actually start to do it. The last thing is the true commitment phase. At this phase, the users produce the contents, for example consumer reviews, buy data and ranking, which make it worth for the other users. They also become the loyal users who persuade the other users to make use of the web services. [14]

Inducing viewer participation is to persuade viewers to engage in iTV program. If the designers push the viewers into participating in the program without enough persuasion, they do not know exactly what to do and why they do it so that they ignore completely the designers' invitation to the end. Thus, the designers need to take into account the strategy based on the behavior chain. This strategy outlines an ideal form of viewer participation and divides it into several phases. Subsequently, each phase should be established to mean a series of successive stimulus-response chains. That is, the designers have to set up a goal as a response that they want to attract from the viewers and come up with several measures and materials as a stimulus. Most importantly, the response of the previous phase has to be the stimulus of the subsequent phase. The viewers' behavior patterns are gradationally reinforced toward the ideal form of viewer participation, taken as a whole.

\section{A New Design Process for Viewer Participation in iTV Program}

The design process for viewer participation in iTV program must reflect entirely the key elements of interactive experience based on narrative, as mentioned before. To achieve it, we integrated the persona-based scenario with the framework of the behavior chain for online participation, and modified them for the planning process of iTV program. As a result, we draw the design process that consists of three stages: narrative, persona, and participation, as shown (Fig. 1).

\subsection{Narrative}

A background story should be designed first in the narrative stage. It is typically made up of key ideas, concepts, progress methods, characters, final goals, and etc. in terms of program narrative. [5] All possible roles that make viewers engage in iTV program 
are organized on the basis of the background story. For instance, the Angel's Gate 4 has the background story in which the start-up entrepreneurs must pass the tests suggested by the angel investors as judges so as to receive investment funds to make their business ideas work. The producers considered the narrative context in depth, and constructed the roles of small investor and partner that the viewers can take an active part in assisting the start-up entrepreneurs.

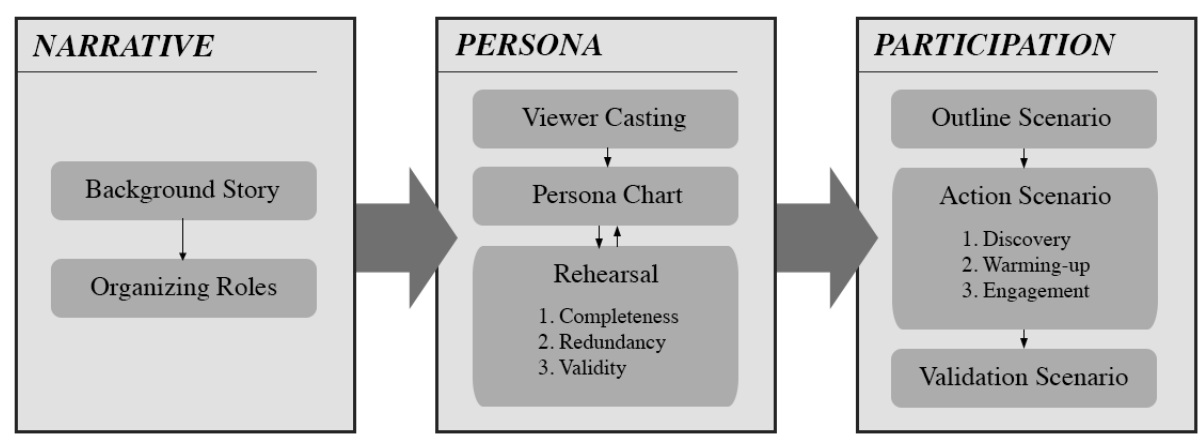

Fig. 1. A new design process for viewer participation in iTV program

\subsection{Persona}

The next stage is the persona in which the designers have to cast viewers suitable for the roles constructed in the previous stage. "Viewer Casting", in here, means that viewers are segmented on the basis of particular standards, and then target viewers are selected. This part needs research data on the viewers above everything else. It would be good practice to make full use of existing materials or to obtain reliable data by conducting researches. For instance, after the designers classify the types of viewers into audience, participant, and performer according to the participation level in advance, conducting objective researches on each type. The designers can properly assign the roles to every type based on the researches. If the research of the target viewers goes well, the meaningful materials are arranged for designing the personas.

The completed personas include imaginary identity, goal, personality, life style, and so on. However, these must go through the process of inspection, which we called "rehearsal", to check for the seamlessness of the link between the roles and the casting. For this, we borrowed the three valuation criteria from Cooper's methodology: completeness, redundancy, and validity. The completeness is to check that the personas reflect all of the essential characteristics that are discovered in the researches. The redundancy is to make sure that the personas are kept distinct from each other. If a redundancy is found between some personas, these have to be integrated or discarded. Lastly, the validity is to ascertain whether the personas describe its target viewers realistically. [13]

\footnotetext{
${ }^{4}$ Angel's Gate was the interactive reality show of Channel NewsAsia (Singapore) since 2011.
} 


\subsection{Participation}

After the personas are constructed, the designers have to sketch out in what way the personas engage in program narrative, what dynamic relationships are formed, and how the two aspects influence the progress of the program. This is just the outline scenario. This scenario must be written to give an overview of viewer participation, not to describe each persona's behaviors precisely. The detailed descriptions of that are dealt with in the next phase, the action scenario. This scenario has to describe how the personas' participations are getting to be intensified according to the following three phases. [14] The first is the discovery phase in which the personas find an iTV program and learn of it, and vice versa. Suppose they have interest in the program, they will join its interactive service and decide to participate in it. Perhaps, they will try doing several things related to the service. This is the second phase that we called the warming-up. The third is the engagement phase in which the personas buckle down to the interactive activities with relation to the program. Above all, in the action scenario, the designers must show the seamless flow definitely from the discovery, warming-up to engagement. The last thing of the participation stage is the validation scenario in which the designers must check that the personas reinforce their interactions in accordance with a narrative context. Besides, they should suppose operational problems or external and subordinate circumstances and then suggest solutions to the problems.

\section{The Viewer Participation of the Hae-un-dae}

\section{$5.1 \quad$ The Narrative}

The Background Story. Hae-un-dae is the sea cloud-capped city of skyscrapers. The rich man is a millionaire and hidden ruler of the city. He believes that human selfinterest is a fountain of wealth and truth of the world. Therefore, he often enjoys letting people take a test on condition of offering jackpot. His test is simple. The people who want to participate in the test only need to take an elevator with a partner, but they must accept the dilemma that a partner today becomes an enemy tomorrow. Only one who reaches the rich man's penthouse will win the jackpot if winning the showdown with the rich man.

The Roles. We constructed the four roles from the background story. The first role is the rich man who controls everything of the Hae-un-dae. The second role is the challenger who gets in an elevator with a partner to participate in the rich man's test. The third role is the conditional assistant that we called "guardian" in our program. He/she is supposed to receive a proportion of the prize money in return for helping the challenger. Lastly, the fourth role is the watcher who does not accept any activities except for watching the program. The watcher has the potential to become the conditional assistant depending on the situation, however. 


\subsection{The Personas}

The Viewer Casting. The casting was limited to the challenger, conditional assistant, and watcher ${ }^{5}$, and it was implemented based on the viewer types by the participation level_-performer, participant, and audience. To secure the reliability of the casting, we referred to the existing researches authorized by the national research institutes related to media. [15][16]

The Persona Chart. We compiled the persona chart that summarized the key characteristics of the challenger, conditional assistant, and watcher revolving around their media usage.

\begin{tabular}{|c|c|c|}
\hline Challenger (Performer) & \multicolumn{2}{|c|}{ Conditional Assistant (Participant) } \\
\hline \multirow{5}{*}{$\begin{array}{l}\text { Media Usage: } \\
\text { 1) She can search for and install necessary apps. } \\
\text { 2) She tends to use well-known apps } \\
\text { or recommended apps by her friends. } \\
\text { 3) She chats away on and on with her friends } \\
\text { through Kakaotalk (the messenger app). } \\
\text { 4) She posts her photos on facebook very often. } \\
\text { 5) While she is at home, she usually watches TV programs } \\
\text { through a TV set, not a mobile devices. } \\
\text { 6) Recently, she enjoys watching TV programs, } \\
\text { through pooq (the paid VOD app) } \\
\text { on her way to and from work. }\end{array}$} & $\begin{array}{l}\text { "I wanna be } \\
\text { more terrific } \\
\text { in the online } \\
\text { than } \\
\text { the reality." }\end{array}$ & $\begin{array}{l}\text { Jniv. Student } \\
\text { Seoul, Korea } \\
\text { Single }\end{array}$ \\
\hline & \multicolumn{2}{|c|}{$\begin{array}{l}\text { Media Usage: } \\
\text { 1) He is very competent in solving problems with apps. } \\
\text { 2) He recommends useful/funny apps to his friends as an early adapter } \\
\text { 3) He enjoys playing social games/online games with his friends. } \\
\text { 4) He watches TV over his smartphone or table PC in general. } \\
\text { 5) He rarely lets the smartphone out of his hands, while watching TV. }\end{array}$} \\
\hline & Watcher (Audience) & "I often get \\
\hline & $\begin{array}{l}\text { Name: Jun, Ji Yeong } \\
\text { Career: Civil Servant } \\
\text { Age: } 40 \\
\text { Location: Seoul, Korea } \\
\text { Marriage: Married }\end{array}$ & $\begin{array}{l}\text { vicarious } \\
\text { satisfaction } \\
\text { in watching } \\
\text { winners of } \\
\text { quiz shows." }\end{array}$ \\
\hline & \multicolumn{2}{|c|}{$\begin{array}{l}\text { Media Usage: } \\
\text { 1) She uses her smartphone mainly for communication; messenger, SNS, etc. } \\
\text { 2) She prefers to use PC rather than smartphone when searching for info. }\end{array}$} \\
\hline
\end{tabular}

Fig. 2. The persona chart of the Hae-un-dae

The Rehearsal. It is needed to definitely distinguish between the challenger (performer) and the conditional assistant (participant) because they showed the similar behavior patterns in an aspect of the media usage. Accordingly, we redefined the characteristics of their media usage and completed the personas chart at last.

\subsection{The Participation}

\section{The Outline Scenario}

1. Da Un and Dong Hyeon got to know the Hae-un-dae through TV promotions, online news, and social networking services. They installed the app of the Hae-un-dae and tried playing the true or false quiz game with curiosity.

${ }^{5}$ The rich man corresponds to the role of the producers so that we excluded it in the viewer casting. 
2. Da Un was fascinated by the huge prize money and the rich man's penthouse, thereby determining to appear on the program. She strived to score over 1 million points in the true or false quiz game to receive an invitation card (the casting call) from the rich man (the producers). Eventually, she made it!

3. Dong Hyeon was fascinated with the mobile quiz game itself so that he was absorbed in playing the game. He desired to boast his highest rank of the game world to his friends or acquaintances. Moreover, he was also interested in the new television game show and consistently paid attention to the progress of the Hae-un-dae.

4. In the online live broadcast (the first round), Da Un took the elevator set on the studio with another challenger who she had never met before. They started to play true or false quiz game that was identical to one of the app. Her team was the first to arrive at the middle story of the building as the final destination of the first round. Thus, Da Un and her partner made it to the live broadcast game show (the second round). Because they missed relatively few quizzes, they only lost 15 million won of 50 million won as the total prize money.

5. Dong Hyeon played the same quiz game through the app just like Da Un while watching the online live broadcast. Furthermore, his prediction was right on, which she got through to the second round, so that he became one of her guardians.

6. Ji Yeong saw the banner advertising related to the online live broadcast of the Haeun-dae during online shopping. She visited it out of curiosity and got to be fascinated with the new form of broadcast quiz show. Eventually, she started to engage in the program by predicting and selecting the second round's challenger.

7. In the live broadcast game show, Da Un and her partner took the separate elevators as the open set located in front of the high-rise building in the city, Hae-un-dae. They must compete in the rising and falling quiz game and reach the rich man's penthouse before the opponent. Da Un was the first to arrive there by solving more quizzes in a short time. Dong Hyeon, who was the guardian of Da Un, was chosen at random during the rising and falling quiz game and played a major role in defeating her opponent by solving the difficult quizzes on her behalf.

8. Finally, Da Un triumphed the rich man in the last true or false quiz game so that she won the prize money. Her guardians including Dong Hyeon received a proportion of hers.

The Action Scenario. The action scenario of the Hae-un-dae was written out according to the three phases as mentioned in (4.3). However, we skipped over the action scenario because it was too long to be covered in this paper. Given that the outline scenario showed the main storylines of the action scenario, the discovery phase of the action scenario corresponds with no. 1 of the outline scenario. Likewise, the warmingup and engagement are accord with from no. 2 to 3 and from no. 4 to 8 respectively.

The Validation Scenario. A large number of the true or false quizzes are needed in order that the same true or false quizzes are not repeated whenever the viewers play the quiz game on the app. To solve this problem, we let the viewer set personally the true or false quiz limited to 40 letters or less. The quiz is automatically listed on the app if more than one person recommends the quiz. The person whose quiz was listed 
on the app can receive a prescribed game point. They can also have the so-called agency experience by getting feedbacks on their participation immediately.

\subsection{The Visualization}

After the viewer participation of the Hae-un-dae was completed, we produced the trailer and the draft of the app to explain it a bit more effectively.
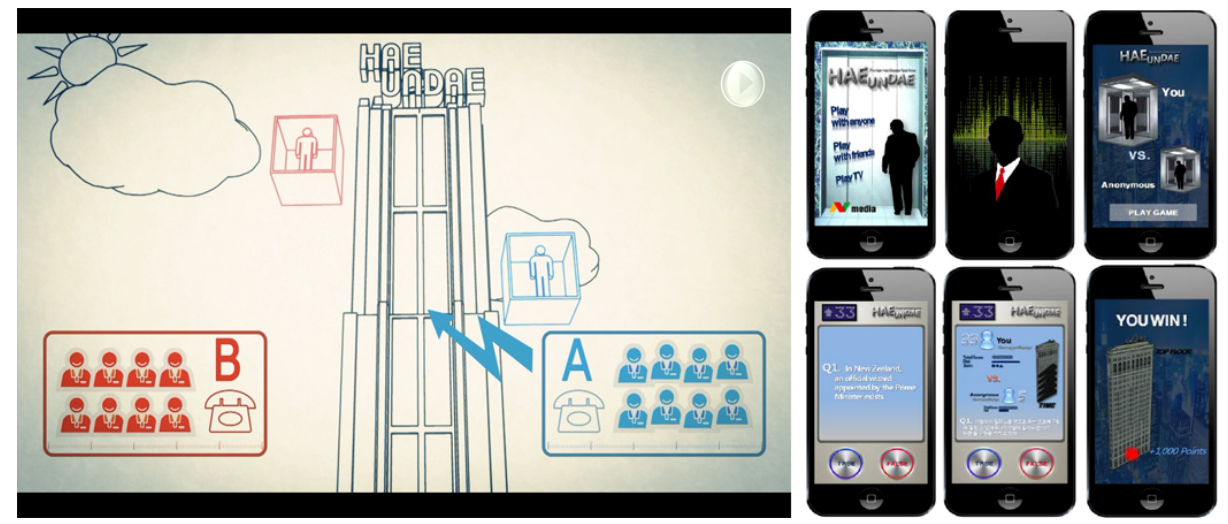

Fig. 3. The trailer (left) / The draft of the app (right)

\section{Conclusion}

We constructed a new design process for viewer participation in iTV program and applied it to the iTV game show Hae-un-dae in practice. This design process has the following significances. Most of all, it handles the real issues that the designers are confronted with during the planning process of iTV program. We colligated the theoretical frameworks with the practical experiences to solve the issues, and therefore, we could create the design process suitable for the practice of iTV program. Furthermore, it is the effective mechanism that led to a greater intercommunication between the two groups, which have had different cultures, in terms that the Hae-un-dae was the academic-industrial collaboration.

However, there are the following limitations when applying our design process to the Hae-un-dae. In fact, it was developed under the practical necessity while planning the program. Therefore, it was applied from the middle stage of the development and mainly utilized for reviewing and improving the semi-finished viewer participation. For this reason, we could not have enough time to conduct the viewer researches before constructing the personas. Moreover, this paper could not deal with any reviews from academia, industry, and viewer because the Hae-un-dae has not been produced and broadcasted yet. If the Hae-un-dae will be released in the near future, we can obtain objective and meaningful data by being evaluated from practitioners and researchers involved in the field of iTV as well as the viewers. 
Acknowledgments. This paper was supported by MSIP (Ministry of Science, ICT and Future Planning), Korea, under the support program for producing bi-direction TV programs.

\section{References}

1. Cesar, P., Chorianopoulos, K.: Interactivity and User Participation in the Television Lifecycle: Creating, Sharing, and Controlling Content. In: Proceedings of the 1st International Conference on Designing Interactive User Experiences for TV and Video, pp. 125128. ACM, New York (2008)

2. Ursu, M.F., et al.: Interactive TV Narratives: Opportunities, Progress, and Challenges. TOMCCAP 4(25), 1-39 (2008)

3. Murray, J.H.: Transcending Transmedia: Emerging Storytelling Structures for the Emerging Convergence Platforms. In: Proceedings of the 10th European Conference on Interactive TV and Video, pp. 1-6. ACM, New York (2012)

4. Hand, S., Varan, D.: Interactive Narratives: Exploring the Links between Empathy, Interactivity and Structure. In: Tscheligi, M., Obrist, M., Lugmayr, A. (eds.) EuroITV 2008. LNCS, vol. 5066, pp. 11-19. Springer, Heidelberg (2008)

5. Hong, S.C., et al.: Creating Television Program Format. Hanul Press, Seoul (2010) (in Korean)

6. Kim, Y.Y.: Interactive Media and Plays. Communication books Press, Seoul (2007) (in Korean)

7. Laurel, B.: Computers as Theatre. Addison-Wesley, Boston (1991)

8. Murray, J.H.: Hamlet on the Holodeck: The Future of Narrative in Cyberspace. Free Press, New York (1997)

9. Mateas, M.: A Preliminary Poetics for Interactive Drama and Games. Digital Creativity $12,140-152(2001)$

10. O'Hara, K., Grian, H., Williams, J.: Participation, Collaboration and Spectatorship in an Alternate Reality Game. In: Proceedings of the 20th Australasian Conference on Computer-Human Interaction: Designing for Habitus and Habitat, pp. 130-139. ACM, New York (2008)

11. Montola, M., Waern, A.: Participant Roles in Socially Expanded Games. In: Strang, T., Cahill, V., Quigley, A. (eds.) Pervasive 2006 Workshop Proceedings, Pergames 2006, Workshop of Pervasive 2006 Conference, pp. 165-173. University of College, Dublin (2006)

12. Kim, J.W.: An Introduction to Human Computer Interaction: The Principle and Method of UX Innovation. ahn graphics, Seoul (2005) (in Korean)

13. Cooper, A., Reimann, R., Cronin, D.: About face 3: the essentials of interaction design. Wiley, Indianapolis (2007)

14. Fogg, B.J., Eckles, D.: The Behavior Chain for Online Participation: How Successful Web Services Structure Persuasion. In: de Kort, Y.A.W., IJsselsteijn, W.A., Midden, C., Eggen, B., Fogg, B.J. (eds.) PERSUASIVE 2007. LNCS, vol. 4744, pp. 199-209. Springer, Heidelberg (2007)

15. Jung, Y.C., Kim, N.D., Kim, Y.H.: 2012 Audience Behavior Survey. KISDI Policy Report. 12-08, 1-584 (2012)

16. 2012 Media \& Consumer Research, http://www.kobaco.co.kr/information/studydata/studydata_ research_annual.asp 